\section{Breast-screening trials are ethical}

The ethics have been questioned of running new randomized controlled trials to determine the benefits and possible harms of population screening for breast cancer (see go.nature. $\mathrm{com} / \mathrm{vw} 13 \mathrm{jv}$ ). As an ethics representative on the Swiss Medical Board, I believe that there is a moral requirement for this type of study. We need to ascertain whether advances in treatment have cancelled out the benefits of early diagnosis through screening.

The random allocation of women into groups that have mammograms with different detection thresholds (see H. G. Welch The New York Times 29 December 2013; go.nature.com/scyt6b) or no mammogram would be ethically problematic if we knew that screening provided a significant net benefit. But this has not been established.

I contend that most women would prefer to participate in a trial that helps to clarify the benefit of screening, rather than continuing to be subjected to screening of doubtful benefit and with potential for significant harm through overdiagnosis. Nikola Biller-Andorno University of Zurich, Switzerland. biller-andorno@ethik.uzh.ch

\section{Pollination curbs climate risk to cocoa}

Cocoa yields will be 75,000 tonnes short of those predicted for the 2013-14 growing season (see go.nature.com/ob6eyt). Supply deficits have been linked to extreme weather events in the cocoa-growing regions of Côte d'Ivoire, Ghana and Indonesia, so future production strategies should take climate change into account (see P. Läderach et al. Clim. Change 119, 841-854; 2013).

The global trade in cocoa is worth US\$10 billion per year, and 50 million people depend on cocoa farming. Farmers are under pressure to stabilize yields, often by increasing chemical inputs and removing shade trees to increase the productivity of cocoa trees. But both strategies could kill vital pollinators.

Farmers need to adopt more sustainable ecological methods. For example, shade trees can make plantations more resilient to drought and provide habitat for pollinators. Increasing insect pollination by as little as $10 \%$ can double cocoa yields (see J. H. Groeneveld et al. Perspect. Plant Ecol. Evol. Syst. 12, 183-191; 2010).

Government and industry sustainability initiatives akin to those run by the World Cocoa Foundation (see go.nature. com/uj9nfh) could contribute to cocoa-pollination research and advise farmers on how best to meet the world's increasing demand for chocolate.

Thomas C. Wanger* University of Göttingen, Germany. tomcwanger@gmail.com ${ }^{*}$ On behalf of 4 correspondents (see go.nature.com/wh86eh for full list).

\section{Citation databases omit local journals}

South America's research impact is underestimated in the main citation databases, as you suggest (Nature 510, 202-203; 2014). However, incorporating the Scientific Electronic Library Online (SciELO) Index into Thomson Reuter's Science Citation Index will not rectify the situation.

SciELO captures only a fraction of the continent's peer-reviewed publications. For example, it indexes papers from just 267 of Brazil's 1,909 journals. Coverage by Elsevier's Scopus database is also inadequate.

According to Latin America's most comprehensive database on scholarly journals, the Latindex Catalog, 4,882 journals in South America meet specified editorial criteria (see go.nature.com/ lbrng2). Scopus includes only 726 of these journals (15\%); regional journals are not eligible (see also go.nature.com/laywal).

That leaves 4,156 journals whose impact is hidden from Scopus. If we assume conservatively that each of these publishes only 20 articles per year by South American authors, then at least 83,120 articles are being overlooked annually.

The commercial databases should close this coverage gap to properly reflect the impact of research in South America. Juan Pablo Alperin Stanford University, California, USA. juan@alperin.ca

\section{Forest devastated by mining is reborn}

Open-pit gold mining leaves millions of hectares of wasteland, particularly in the tropics. A series of affordable, socially inclusive and ecologically sound forest-restoration projects in Colombia could become a model for rescuing mined lands around the world.

Reforestation began in 2002 across 1,290 hectares in Cácerces, one of Colombia's most conflict-ridden regions (see L. G. Moscoso Higuita Reforestation: A Natural Process; Editorial Colina, 2005). Projects using similar techniques have since begun in other areas of the country.

First the barren landscape is reshaped using a bulldozer, and the soil is enriched with composted sewage sludge, benign microorganisms and other nutrients. Next, Acacia mangium trees are planted (because of their hardiness, fast growth and ability to improve soil by fixing nitrogen and providing abundant leaf litter), along with 10-20 native tree species.

After ten years, the A. mangium trees are logged and replaced with well-adapted native species to encourage diversity. The Cácerces site now contains more than 120 different native tree species and harbours an impressive range of wildlife, including jaguars, sloths and several species of primate.

Local people are involved in all steps of the restoration process, and they share in the social and economic benefits generated, such as increased employment and proceeds from timber sales and carbon credits. These will more than compensate for the initial investment of US $\$ 3,000$ per hectare.

Evert Thomas Bioversity International, Cali, Colombia. e.thomas@cgiar.org

\section{Graduate admissions test has some merit}

We would like to clarify a couple of points raised by Casey Miller and Keivan Stassun in their criticism of the US Graduate Record Examination (GRE) for selection of graduate students (Nature 510, 303-304; 2014).

As documented in a metaanalysis by independent researchers, the GRE predicts more than just first-year graduate grades: it also predicts higher-degree attainment, time to complete, research productivity and citation counts (see N. R. Kuncel et al. Psychol. Bull. 127, 162-181; 2001).

And although we acknowledge that the GRE "reflects certain demographic characteristics of test-takers", we reject any implication that this is a fault in the test: rather, test scores reflect the reality that more educational resources are available to students from wealthier families.

We agree that graduate admissions should be based on multiple sources of information, including standardized test scores, undergraduate grades, diligence and non-cognitive factors such as 'grit'.

Brent Bridgeman, David Payne, Jacqueline Briel Educational Testing Service, Princeton, New Jersey, USA. bbridgeman@ets.org 